\title{
The Rate of Local Integration in the Supply Chain of the Renault Maroc Company
}

\author{
Rajaa Raissouni ,M'hamed Hamiche \\ Centre des Etudes Doctorales en Economie et Gestion et Développement Durable \\ de I'Universite Abdelmalek Esaadi, Tangier, Morocco \\ rajaaraissouni@gmail.com;Hamiche2020@gmail.com
}

\section{Introduction}

The automobile industry has become Morocco's leading export market and one of the most successful industrial pillars in the Moroccan industry. First with the establishment of Renault Tanger in 2008, which is the biggest foreign investment in Moroccan history, furthermore with the anticipated arrival of Peugeot-Citroën (PSA) in Kenitra in 2019; therefore, Morocco remains an attractive country for major car makers due to its political stability and favorable geographical position compared to its neighbors in the region.

The development of a solid industrial fabric is the result of further integration of the automotive value chain in Morocco. Indeed, the year 2016 testifies to the signing of supplier agreements called Ecosystem, mobilizing investments of the order of 10 billion dirhams.

These agreements were signed in the presence of His Majesty King Mohamed IV and several ministers as well as the Director of Operations, of the Renault group Middle East and India branch. This project involves developing a global supply platform that generates a figure of 20 billion dirham per year. It will contribute to the creation of 50,000 new permanent jobs with the objective of doubling this number by 2020 to more than 160000. In short, the ecosystem signed in April 2016 includes three types of agreements:

- A framework agreement on the establishment of the Renault ecosystem.

- An industrial property agreement.

- A convention on executive training and vocational training in the automotive sector.

Morocco commits to give subsidies to investments and tax advantages to suppliers who intend to settle within the country. Renault took advantage of this ecosystem agreement by increasing its local integration rate and consequently reducing and optimizing its logistics and purchasing costs.

Generally, the purchasing costs of multinationals such as Renault represent a significant percentage of the cost of their products. To this end, they still hope to optimize them by several levers, local sourcing is a strategic tool to achieve this objective through its direct contribution to the purchasing performance and consequently the company's performance.

This leads us to question the levers and the challenges that this local sourcing represents for the major international structures. In other words, the mean question is: does the increase in the rate of local integration always reduce purchasing costs for multinationals? 
Rajaa Raissouni ,M'hamed Hamiche; The Rate of Local Integration in the Supply Chain of the Renault Maroc

Company. Transactions on Machine Learning and Artificial Intelligence, Vol 5 No 4 August (2017); pp: 123-140

Keywords: Supply chain; Local integration rate ; Automobile industry; Sourcing procedures; sourcing practice.

\section{Sourcing strategies}

Sourcing is the research, location, selection and evaluation of a supplier in order to meet an identified need. However, in a context of globalization, multinationals manage sourcing around the world by managing a global supply chain for their production sites scattered across the globe. To do this, multinationals seek to reduce the logistical costs of their factories by looking for locally installed suppliers who can supply and deliver according to their specific standards.

\subsection{Sourcing strategies according to the supplier panel:}

\subsubsection{The different sourcing strategies}

\section{Sole sourcing:}

It is a single source of supply for one type of product. It can be the result of sourcing from a supplier whose production capacities are rare in the market; But it would be wise to look at the supplier market to compare the supply of other suppliers with the one already contracted.

The use of a single supplier presents a strategic risk insofar as an incident can lead to a break in the supply chain, the consequence of which can be damaging for the enterprise. The link between sole sourcing and supplier relations gives rise to a less formal and longer-term contact. But having a sole sourcing strategy to increase quality is not always true ${ }^{1}$.

\section{Dual sourcing:}

It involves using two suppliers to produce the same component or buy the same raw material. In general the business is shared for $70 \%$ with the supplier $Y$ and $30 \%$ with the supplier $X$. It is in some way a response to the risk of the single source of supply since the supplier acts as a backup in case the other would be failing. Many companies consider dual sourcing as important because it allows the company to have some flexibility as well as avoid being frozen by long-term contracts with a single supplier.

\section{Multi sourcing:}

Multi sourcing is when three or more suppliers are used by the company for the same product. This corresponds to a strategy of diversifying sources of supply when, for example, a parent company orders from a number of suppliers close to its factories and markets a similar product to supply the local demand.

${ }^{1}$ Falguni Sen et William J. Latzko, Single Source Supplier Strategies-An Exploratory Study of the Impact of Values, Attitudes and Practices in Large U.S. Manufacturing Firms. Academy of management Proceedings, 1987, p.301-305 


\subsubsection{Back-up strategies:}

\section{Cross sourcing:}

Cross sourcing is a sourcing strategy in which a company uses a supplier in the production of a good or service for a production domain of the company and another supplier producing the same good or service for another area of production line.

The idea is to have a back up supplier and develop a competition between the two suppliers for future contracts to be awarded. Competition between suppliers is a means of encouraging emulation but should not be an instrument of pressure of the client company on its supplier.

\section{Suppliers of fluctuating demand:}

Some industries experience a peak demand during a season of the year. They use a supplier that produces continuously during the year. During the strong period, one or more other suppliers will support the peak demand. The degree of strategic relationship with the temporary supplier is not necessarily very high. Sometimes it serves as a "spare wheel", thing that hampers to carry out a strategic purchasing policy with a reduction in prices and the appearance of innovation.

\subsection{The Geo-Location of the Company And The Location Of Resources:}

\subsubsection{Local sourcing:}

Local sourcing involves working with regional or national suppliers, defined according to the location of a business activity as a factory. Local sourcing has the advantage of reducing the risks associated with logistics. Another advantage is to benefit from a product delivered with speed, when the freshness of the products is critical or when the demand evolves quickly.

For a company that does not internationalize its sourcing, local sourcing provides, at a lower cost, a developed network of partner suppliers to cover the demand in either local or international markets. However, if these sourcing concerns manufactured product in a declining cycle, low-end, designed by unskilled employees, the local sourcing in certain regions is not advantageous because costs become the first criterion.

\subsubsection{International sourcing:}

International sourcing is possible through the development of transport and telecommunications which makes it more accessible. This international sourcing is used to benefit from a comparative advantage like that of Silicon Valley where innovations are strong because emulation is favored. Thus appears a geography of sourcing where the firms look for quality in some leading countries like France, Japan, Germany and the United Kingdom².

\footnotetext{
${ }^{2}$ AberdeenGroup, Low-Cost Country Sourcing : Success Strategies Maximizing and Sustaining the Next Big Supply Savings Opportunity, Juin 2005
} 
Rajaa Raissouni ,M'hamed Hamiche; The Rate of Local Integration in the Supply Chain of the Renault Maroc Company. Transactions on Machine Learning and Artificial Intelligence, Vol 5 No 4 August (2017); pp: 123-140

International sourcing has developed with the emergence of competitive players outside the borders. With the collapse of the Soviet Union, China's openness, WTO agreements, the development of NAFTA, raw materials, plastics, electronics are bought more frequently from international sources.

This sourcing is adapted when, for manufactured products, the time taken for ship delivery is not paramount. Otherwise the airway remains a possibility to transport in the emergency but its use is very expensive. International sourcing requires taking into account ${ }^{3}$ the total costs of delivery (transport, customs clearance, banking, insurance, quality inspection); Trade regulations, both restrictions and incentives; Time to Market (flexibility); Value-added services (a service which is offered by a supplier and which makes it possible to dispense with one more intermediary); Internet communication tools. The barriers are understanding of international procurement procedures (import licenses, certificates of origin), extended delays, cultural differences, currency risks. Finally, having international suppliers has the effect of increasing the inventory level resulting from a policy of risk reduction ${ }^{4}$ (downtime, terrorism, change, policy) that leads to the accumulation of security stocks.

\subsection{The sourcing procedure}

\subsubsection{Sourcing steps}

\section{Expenditure Analysis, Spend analysis:}

Strategic sourcing begins with spend analysis up to the procurement automation process ${ }^{5}$. Spend analysis refers to cost management. It is a way of analyzing cost structures that can be carried out by product or by product groups. The products purchased and the procedures leading to these purchases are analyzed in great detail.

\section{The proactive specifications:}

Before a sourcing project, the company establishes a general project plan (mapping) in which it formulates its needs, proposes modes of action in the supplier market, makes internal recommendations, identifies the cost sources (cost drivers). It is the stage of constitution of the proactive specifications. This is the preparation stage prior to the decision to attack (as in marketing) the dense supplier market.

Even before the detailed specifications have been drawn up, it must precede a strategic decision by the company's top management. The intention is specified, communicated and comes into application by the constitution of a sourcing team. The latter will attempt to determine the buying segments where the proactive approach to the supplier market can be carried out. Once defined, the team draws up the complete specifications by consulting the other internal clients in order to guarantee the general approval in a strategy of global strategy known to all.

\section{Data collection and processing:}

Any sourcing project, whatever its strategic and geographic orientation, requires the company to collect and analyze all kinds of data in order to prepare the sourcing process and anticipate the risks. This may

\footnotetext{
${ }^{3}$ Sara Ireton, Global Sourcing Checklist. Industry Week, janvier 2007, p. 40

${ }^{4}$ Mike Jones, Domestic costs of foreign sourcing. Material Handling Management, février 2008, p. 40-41

${ }^{5}$ Sean Delaney, Delivering Value in both good and bad times, E-sourcing Forum, 14 juillet 2008
} 
be data from previous sourcing operations: Results, quality of products purchased, and respect of deadlines by the supplier. This may include data on the economic environment such as inflation rates, world commodity prices, exchange rates and the transport network. Also the buyer is required to learn about the legislative environment. The latter can be very changeable and contain legal gaps in some countries; It is necessary for the firm to guard against possible risks due to non-protection by the law, such as intellectual property.

Generally it is necessary to collect the strategic information that will help to establish the sourcing decision, indeed it is necessary to look for 3 important information:

- Geo-location of supplier: this information will allow defining the logistic flows and the daily rates of delivery.

- Quality of supplier and price: An ISO certification of supplier is very important information that proves the quality of the products.

- Production capacity: knowing the supplier's production capacity will make it possible to know its competitiveness and its flexibility towards an unpredictable increase in demand, which generates large investments.

\section{The offers received and selection suppliers:}

Supplier selection is a critical phase in the sourcing process, as it has a significant impact on the company's performance.

Indeed, it is necessary to develop a network of reliable and competitive suppliers so that the company can raise and survive in a competitive environment. However, in order for the company to be able to provide a quality product at a reasonable cost, it must virtually monitor the performance of its suppliers.

However, there are two major problems:

- The determination of the number of suppliers and the mode of relationship with them: this choice is largely influenced by the strategic activity area of the company as well as its management mode,

- The selection of the best suppliers: this problem arises after the determination of the number of suppliers selected, however we will explain in detail in the next section the different techniques designed by researchers in the determination of the best suppliers and the fundamental criteria in the decision of making supplier appointment .

\subsubsection{Supplier selection items:}

\section{Selection criteria:}

Based on a survey of 274 Canadian and American firms that are members of the National Association of Purchasing Managers (NAPM) and in order to theorize supplier selection criteria, Dickson (1966) was able to identify 23 criteria used by companies in the 1960 s to select their suppliers

The study showed that supplier selection is a multi-criteria decision that often involves simultaneous consideration of several criteria such as price, delivery time and quality, and that it is extremely difficult to find a supplier that excels everywhere. For example, the supplier offering the lowest price may not have the best performance in terms of delivery time or product quality. 
Rajaa Raissouni ,M'hamed Hamiche; The Rate of Local Integration in the Supply Chain of the Renault Maroc Company. Transactions on Machine Learning and Artificial Intelligence, Vol 5 No 4 August (2017); pp: 123-140

Indeed, the criteria are classified by degree of importance, the table below, summarizes the different criteria and their classification:

Table 1: Dickson's classification of supplier selection criteria

\begin{tabular}{|c|c|}
\hline Supplier Selection Criteria & \begin{tabular}{|c|} 
Dickson \\
rankings 1966
\end{tabular} \\
\hline Price & 1 \\
\hline dilevry & 2 \\
\hline Quality & 3 \\
\hline production Capacity & 4 \\
\hline geographical Location & 5 \\
\hline Technical capacity & 6 \\
\hline $\begin{array}{l}\text { Management and } \\
\text { organization }\end{array}$ & 7 \\
\hline Positioning in the Industry & 8 \\
\hline Financial situation & 9 \\
\hline Past Performance & 9 \\
\hline Repair Service & 9 \\
\hline Attitude & 10 \\
\hline Packaging capacity & 11 \\
\hline Operations Control & 11 \\
\hline Training and support & 12 \\
\hline Process Compliance & 12 \\
\hline Social relationship & 12 \\
\hline Communication system & 12 \\
\hline Reciprocal relationship & 12 \\
\hline Impression & 12 \\
\hline Passion to do business & 13 \\
\hline Purchase volumes & 13 \\
\hline Warranty Policy & 14 \\
\hline
\end{tabular}

According to Vonderembse (1995), their study indicates that the process of supplier selection is multicriteria and that the most important criteria are in this order: quality, product performance, reliability of delivery, product availability, cost, delay, technical capacity Supplier, after-sales service, financial situation and lastly the geographical location of the supplier.

The study also indicates that performance and product quality are the two most important criteria in selecting suppliers for companies, and recommends that firms reduce the number of suppliers and develop strategic partnerships with suppliers.

\section{Types of relationships between the company and suppliers:}

Masella and Rangoon (2000) grouped these relationships into two phases. Each variable depends on the horizon of the relationship and the degree of integration between the company and the supplier:

\section{The horizon of the relationship:}

We distinguish between a short-term relationship, the occasional (or cyclical) outsourcing and a long-term relationship, such as permanent (or structural) subcontracting. The duration of the relationship depends on several factors, the most important being: 
Transactions on Machine Learning and Artificial Intelligence Vol 5 No 4, Aug 2017

- The level of investment in specific goods such as infrastructure, equipment, information systems, etc. These are the elements that the company must create to make the relationship operational and not to be used in other buying relationships..

- The cost of changing suppliers: It includes the cost of finding new suppliers in the case of low performance or the existence of a significant risk.

The degree of integration between the company and the supplier in logistics and strategic terms:

Logistics integration involves performance arrangements such as quality, service and time. However Strategic integration refers to arrangements that involve the supplier's know-how to develop new products and technologies.

Therefore, the type of relationship between an OD and a provider can be one of the following four scenarios A, B, C and D:

Table 2: Scenario of degree of enterprise-provider integration

\begin{tabular}{|l|c|c|}
\cline { 2 - 3 } \multicolumn{1}{c|}{} & Short term & Long term \\
\hline Logistics integration & $\mathrm{A}$ & $\mathrm{B}$ \\
\hline Strategic integration & $\mathrm{C}$ & $\mathrm{D}$ \\
\hline
\end{tabular}

To determine the selection criteria for each of these scenarios, the supplier is modeled as a dynamic system, presented by three types of variables:

- Output variables: They correspond to the performance of the supplier and are of two classes: manufacturing performance such as cost, quality, delay, flexibility and service, and technological performance such as innovation of products purchased.

- Input variables: These include control variables used by the supplier to complete a certain performance and environmental variables such as market developments, competitor actions which are not completely under the control of the supplier.

- The state variables: They are responsible with the input variables of the dynamics of the output variables of the system which is the supplier. To define state variables, resource-based theory is used.

Contrary to the fact that the competitiveness of the firm is measured in terms of cost or performance measured directly on the current product in the long term. Thanks to this vision, this competitiveness is measured through the allocation of resources. These are unique, durable and difficult to imitate or substitute, hence the infrastructure implemented by the supplier. These infrastructures are linked to manufacturing resources (organization of manufacturing, human resources management, production planning, information system, etc.) or to technical resources (organization in research and development, staff qualification, investment Research laboratories and control equipment, relations with external experts, etc.). Thus, for each type of relation, the proposed model defines the criteria corresponding to the selection of the suppliers.

In conclusion, the selection of suppliers is a very complex process, which depends on several factors such as the company's sector of activity, the type of relationship to be undertaken between the company and 
Rajaa Raissouni ,M'hamed Hamiche; The Rate of Local Integration in the Supply Chain of the Renault Maroc Company. Transactions on Machine Learning and Artificial Intelligence, Vol 5 No 4 August (2017); pp: 123-140

the suppliers, and so on. The various works in this field show, however, that the triptych QCD (Quality, Cost, Delay) remains the most used in this process.

These and other criteria are sometimes conflicting, making the process of supplier selection complicated. Several methods have been established for solving this problem. The following paragraph presents a state of the art of the main methods.

\section{Presentation of the local integration project and diagnosis of the perimeter body \& Electrical}

\subsection{Presentation of the local integration project and its role in improving purchasing performance}

\section{General presentation: Local integration of automotive parts:}

This trend is motivated by the gains to be made in terms of geographic proximity, lower logistics costs and exchange rate risks. To benefit from the cost advantage, Renault Maroc is looking for local partners for business opportunities in order to establish a Win-Win relationship and also minimize logistical costs.

The supplier's competitiveness remains the main concern of Renault Maroc. To this end, it accompanies these suppliers with the ANPQP (Alliance New Product Quality, Procedure) approach, which is founded by Renault-Nissan to make annual agreements and provide specialized teams for suppliers to transfer knowhow, especially in terms of quality management and competitive production.

The ANQP is the common procedure to cover all the quality assurance activities expected for the POE (Outsourced Product of the Renault plants). It was developed to define the common requirements of Renault and Nissan towards their suppliers from the initialization of the project, through the manufacturing agreement, to the end of production series. The challenge is therefore to reach the objectives qualities, cost, delivery time and overall expectations of the customer.

The problem that generally arises for the design of automobile parts in Morocco is the lack of technology and experience. Indeed, the Moroccan industrial fabric does not have the technologies necessary for the manufacture of high quality parts or the human skills necessary for the realization of a project of high posture. However, there are multinationals, established in Morocco to fill the gap, and already part of the Renault-Nissan supplier panel.

The criteria requested by Renault-Nissan Purchasing Organization (RNPO) is a joint purchasing organization between Renault and Nissan, which was set up in 2001 and has gradually evolved to cover $100 \%$ of purchases since 2009. Common purchases Mean that Renault and Nissan have mandated RNPO to build a business panel and monitor the performance of suppliers), for the choice of suppliers is grouped in 4 primary parts: 


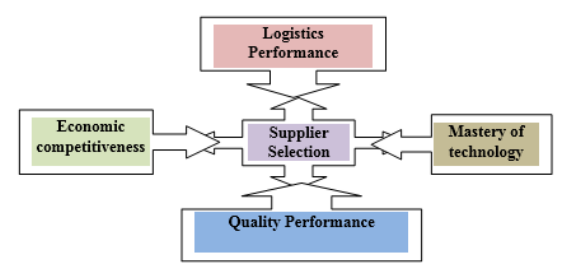

Figure 3: Supplier Choice Criteria at RNPO

Local integration is an effective tool for cost reduction, but the process is slow and requires heavy investment of tools and studies. A profitability study is carried out at the end of the consultations to decide on the profitability of the project for Renault.

Today, the rate of local integration is $33 \%$, which remains very low compared to the targets set at the start of the Renault Tangier plant.

Indeed, the last supplier agreement signed in April 2016, and the establishment of ecosystems, will allow Renault to boost this rate of local integration thanks to permanent support from the Moroccan State, specifically the Ministry of Industry for The development of the industrial fabric in Morocco. The objective is to achieve a local integration rate of $65 \%$ by 2023 , which remains a challenge for both stakeholders namely Renault and the Moroccan State. So the local integration project takes into account not only the optimization of costs but also the commitment vis-à-vis the government.

\section{SWOT analysis of local integration:}

The SWOT analysis of local integration will enable us to identify, on the one hand, the components on which we can rely and count, and on the other hand, the weaknesses that need to be reinforced. Here is the SWOT analysis:

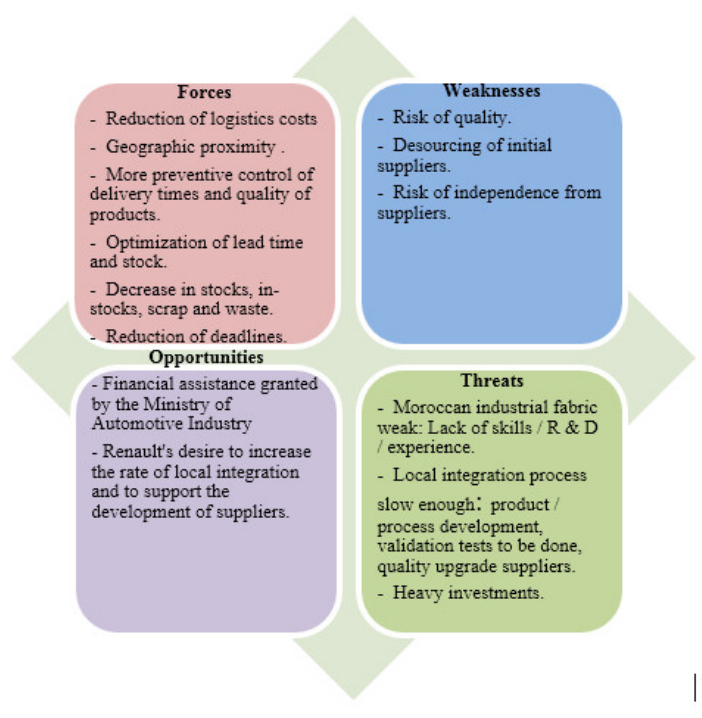

Figure 4: SWOT Analysis of Local Integration

\section{Local integration steps:}


Rajaa Raissouni ,M'hamed Hamiche; The Rate of Local Integration in the Supply Chain of the Renault Maroc Company. Transactions on Machine Learning and Artificial Intelligence, Vol 5 No 4 August (2017); pp: 123-140

The process of local integration takes place in several stages, from the determination of the perimeter impacted up to the appointment of the supplier, which makes sense, since sourcing is a flexible process that changes according to sector of activity and the nature of the business. Below the different actions carried out for each stage of local sourcing:

Step 1: Determine the scope of action:

In this phase, the following elements are specified:

- Identification of the parts concerned.

- Identification of projects.

- Identification of customer sites.

- Determination of current suppliers.

- Identification of diversity (All existing references), and calculate the mix of references by several criteria either by volume, power train, or product range, the choice of mix depends on the nature of the part.

- Location.

- Prospecting and determination of suppliers to consult (visiting local suppliers, consulting current foreign suppliers for a possible establishment in Morocco).

\section{Step 2: Selection Criteria:}

In this phase, we determine our supplier selection criteria, which are: Geo-location (Integrated multinational suppliers)

- Economic competitiveness.

- Technological mastery.

- Logistics performance.

- Quality performance.

Step 3: Define local integration scenarios:

After defining the selection criteria, it is recommended to draw a road map for possible scenarios of the local integration.

Step 4: Recovery of engineering definition:

Engineering prepares the technical definition in parallel with the purchase for 3D modeling and 2D of the part.

\section{Step 5: The sending of consultation files to the supplier (Request for information):}

The purchase sends the RFI file. This is the equivalent of the purchase specification.

\section{Step 6: Kick-off meeting with suppliers:}

The purpose of this meeting is to discuss the investments necessary for the start-up of the manufacture of the part

Step 7: Launching of logistics costing : 
To calculate the necessary transport costs, and compare the new and the old logistic path.

Step 8: Comparative Analysis, Supplier Returns:

A comparison of the offer of new supplier and the offer of the current supplier, it is done on the following points:

- Price comparison.

- Comparison of logistics costs.

- Comparison TEI (Investment Ticket).

- Comparison of delivery times.

- Comparison of quality.

\section{Step 9: Purchase Negotiation:}

This stage of negotiation is essential for building a lasting relationship with the supplier.

Step 10: Appointment of Supplier:

The supplier is appointed for the delivery of the part.

Step 10: Appointment of Supplier:

The supplier starts the manufacturing process of the part.

Finally, this step is the standard procedure for a local sourcing project, the order of these steps differs from one project to another.

Before starting the project of our integration we will first analyze the inventory of the perimeter purchase Body \& Electrical.

\section{Analysis of the state of the premises and diagnosis of the perimeter body \& Electrical:}

\section{Inventory of fixtures:}

The starting point of the project is to do an analysis of the Body \& Electircal perimeter of Renault Maroc. The perimeter that will be analyzed corresponds to everything related to the body of the car and the electronic elements and systems that constitute it.

The Body \& Electircal perimeter is made up of 5 buyers, each one dealing with a number of parts and their suppliers. Some of these parts are locally integrated and another part is not. To do that, we tried to develop a supplier panel so that we could have more visibility.

In this perimeter there are 4 families of purchases, below a table that summarizes all the types of purchases in this perimeter: 
Table 5: on the Body \& Electrical perimeter parts panel

\begin{tabular}{|c|c|}
\hline Body Equipment Purchasing & $\begin{array}{l}\text { - Glazing. } \\
\text { - Watertight seal. } \\
\text { - Wing mirror. } \\
\text { - Lighting. } \\
\text { - Wiping. }\end{array}$ \\
\hline Purchases climate and cooling system & $\begin{array}{c}\text { - Air conditioner. } \\
\text { - Radiators. } \\
\text { - Radiator hoses. } \\
\text { - Compressors. } \\
\text { - GMV: Ventilation motor } \\
\text { unit. }\end{array}$ \\
\hline Purchasing Multi-Media and Mechatronics & $\begin{array}{l}\text { - Clusters. } \\
\text { - Door mechanism. } \\
\text { - Hinge. } \\
\text { - Switch. } \\
\text { - Combi switch. } \\
\text { - Door switches. } \\
\text { - Electronic keypad. } \\
\text { - Probes. } \\
\text { - Speakers. } \\
\text { - Antenna. } \\
\text { - Microphone and } \\
\text { displays. } \\
\text { - Radio / Navigation } \\
\text { system. }\end{array}$ \\
\hline Buying Harness, Energy Systems & $\begin{array}{l}\text { - Wiring. } \\
\text { - Drums. } \\
\text { - Starter. }\end{array}$ \\
\hline
\end{tabular}

Indeed, five buyers share among them these parts, their management, their supplier panel, and supply monitoring.

Indeed, this perimeter is very strategic, since it gathers a very interesting percentage of all parts worked on vehicles. That said, buyers must have background and training in the technical field and specifically, in mechanical and electronic engineering to handle negotiations very well with its supplier.

We have chosen the group of merchandise climate and cooling system, for a possible local integration, however before beginning the consultations, we have made a small diagnosis of this grouping of merchandise to study the parts not yet integrated locally and those potentially to be there in 2016.2016.

Diagnosis and analysis of the parts group Climate and Cooling System: 
We have created a table that includes all the families of purchases and the parts allocated to them. Subsequently the document was sent to the buyer who is responsible for the perimeter climate and cooling, so that he can tell us which purchasing families he is responsible for, their suppliers solicited and the parts that are integrated locally and have not yet been.

This support will help us to have a visibility on the parts that can be integrated locally and to identify it in order to launch the supplier consultations on these parts.

Table 6: analysis of the climate and cooling system

\begin{tabular}{|c|c|c|c|c|c|c|}
\hline \multicolumn{2}{|c|}{$\begin{array}{c}\text { The parts of the climate perimeter } \\
\text { and cooling system }\end{array}$} & \multirow{3}{*}{$\begin{array}{l}\text { buyers } \\
\\
X\end{array}$} & \multirow{2}{*}{\begin{tabular}{|c|} 
Local \\
integration \\
2016 \\
No
\end{tabular}} & \multirow{2}{*}{$\begin{array}{c}\text { Suppliers } \\
\\
\begin{array}{c}\text { Hutchinso } \\
\mathrm{n}\end{array}\end{array}$} & \multirow{2}{*}{$\begin{array}{l}\text { City } \\
\\
\text { Spain }\end{array}$} & \multirow{2}{*}{$\begin{array}{c}\text { Integrated Potential } 2017 \\
\text { Yes }\end{array}$} \\
\hline \multirow{8}{*}{$\begin{array}{c}\text { Climate and } \\
\text { cooling } \\
\text { system }\end{array}$} & Compressors & & & & & \\
\hline & HVAC manual & & Yes & Denso & Tanger & \\
\hline & HVAC regulated & $Y$ & Yes & Denso & Tanger & \\
\hline & GMV & \multirow{5}{*}{ Z } & Yes & Suit/Gate & Tanger & \\
\hline & Air guide & & Yes & Sews & Kenitra & \\
\hline & Radiator & & Yes & $\begin{array}{l}\text { GFD/Calso } \\
\text { nic }\end{array}$ & Berrechid & \\
\hline & Radiator hoses & & No & $\begin{array}{c}\text { Tristone/S } \\
\text { uperindus } \\
\text { India e }\end{array}$ & Inde & Yes \\
\hline & $\begin{array}{c}\text { Hoses for water } \\
\text { evacuation }\end{array}$ & & Yes & $\mathrm{MGI}$ & El-Jadida & \\
\hline
\end{tabular}

This table is a summary on the integrated parts and the others that are potentially integrable for the year 2017 and for which we already have an idea on the feasibility of the project. This table contains the following:

- Suppliers solicited for each commodity group.

- $\quad$ The parts that will be integrated for the year 2016.

- Potentially integrable parts for the year 2017.

After drawing up this table, the engineering department and the project purchases made a meeting to choose between the compressors and the radiator pipes for a possible local integration. We found that there is no international supplier installed in Morocco that would have the necessary technology to produce compressors of good quality. In the end Renault chose to start on the local sourcing of radiator pipes. 


\section{The project framework}

We concluded that MGI will be interested in the supply of radiator pipes as shown in the table above shows that Renault has already integrated locally at MGI El-Jadida. The water drain pipes that are more or less similar in their production than the radiator pipes, in addition MGI already has an experience effect in the production of radiator pipes since they produce this type of parts in its plants everywhere In the world for Renault and for other car manufacturers.

The choice of radiator pipes was validated by the engineering department, as well as the purchase projects including with the approval of Chamberlain Nicolas project manager local integration Renault Morocco. The supplier MGI with its new site in El-Jadida represents an opportunity to be seized by Renault. The table below summarizes the different levers of this project:

Table 7: Project Framework Summary

\begin{tabular}{|c|c|}
\hline Target Supplier & MGI El-Jadida \\
\hline Actual Supplier & Superindus India \\
\hline Year of projection & $2017 / 2018 / 2019$ \\
\hline Turnover & 300 000Euro \\
\hline Projects & Lodgy, Sandero, Dacia Logan, Docker \\
\hline Impacted perimeter & $\begin{array}{c}\text { Radiator Inlet Hose } \\
\text { Radiator Outlet Hose } \\
\text { Heat Inlet Hose } \\
\text { Hose outlet radiator heating } \\
\text { Hose intake tank degassing } \\
\text { Hose outlet tank degassing } \\
\text { Hose purge }\end{array}$ \\
\hline
\end{tabular}

A precision, to clarify the confusion between the nature of the part and the references. Each part has a number of references, in the case of this project there are 800 references for the family of radiator pipe parts. The reference is a code which designates the technical characteristics of the part.

\section{Consultation phase}

Generally this phase is subdivided into two main components:

The development of the purchase specifications:

In the Renault standard the purchase specification is constituted in the form of an RFI, Request for information. Indeed for the realization of the mission it is necessary to collect different information from different departments so that the file is in good and due form.

\section{The volume of vehicle projects:}

At Renault each vehicle is associated with a specific code and a project manager responsible for the monitoring of the sourcing carried out. To do this consult the project managers purchase to have the volumes impacted by our sourcing on each type of vehicle namely: Docker, Dacia Logan, Sandero, lodgy. Indeed, the designation of the volumes for the consultation is done according to a well-defined purchase strategy, to simplify, the project managers buy have two different volumes for each project, the first is 
the average volume and the second $c$ 'Is the maximum volume, this difference is due to the unpredictability of the scenarios throughout the duration of the project.

Generally, consultations are conducted on average volumes. This is what we did, for the simple reason that if the supplier is competitive on the average volume, it will automatically be competitive on the max volume.

\section{Mix volumes and references:}

The second information to be included in the RFI is the Mix volumes and references. The Mix volume is the criterion for which the supplier must return the volume of the previous table. In addition, since we do sourcing to radiator pipes, we must consider the types of motorization and the different mechanical aspects of the parts.

This information is retrieved from the engineering department. They provide us with the references of each type of radiator hoses and their mix with respect to the existing engines.

The references are like an engineering code that defines the degree of injection per second and the different mechanical dimensions. This information is strictly confidential. We were able to retrieve a table on the analysis of different types of motorization with their mixes in an anonymous way.

\section{Quality Renault:}

The purchasing function is a transversal function. This is reflected in the RFI's drafting, which must specify the quality standards that Renault requires from its supplier.

To do this, the quality department recovers the quality objective of Renault for the years $(2016,2017$, $2018,2019)$ of the radiator pipes, as well as the degree of incident tolerated by quarter. This last criterion is measured by what is called the PPM indicator. This is means incident by thousands.

- For example: a PPM = 5 goal, means that in a number of 1000 parts delivered to the Renault site, the degree of scrap and non-conforming parts must not exceed 5.

Indeed, Renault is developing another quality indicator for its suppliers. This is the ranking. It classifies its suppliers and awards a quality rating based on the experiences with the supplier, as well as its reputation and ISO quality certifications

After the recovery of the quality objectives, it is necessary to do the same for the logistics side. Except that the objectives of the logistics are the same as the previous year with the precision of the incoterm FCA. This precision gives transport responsibility to Renault.

\section{The technical file:}

The purchasing file consists of two main elements: the RFI and the technical file. The responsibility for the elaboration of this last one weighs on the shoulders of the engineers.

In fact, this file contains the technical definition of the parts, specifying the 2D and 3D models, and the technology used for quality production and consistent with Renault standards.

\section{Analysis Phase}

The following two indicators need to be analyzed: 
- Transport encryptions.

- Current CA analysis.

\section{Transport encryption:}

In order to calculate the transport gains that Renault can generate from this project, it is necessary to carry out a transport calculation, comparing the current logistic flow and the future flow of the radiator pipes. Below is a diagram of the two flows:

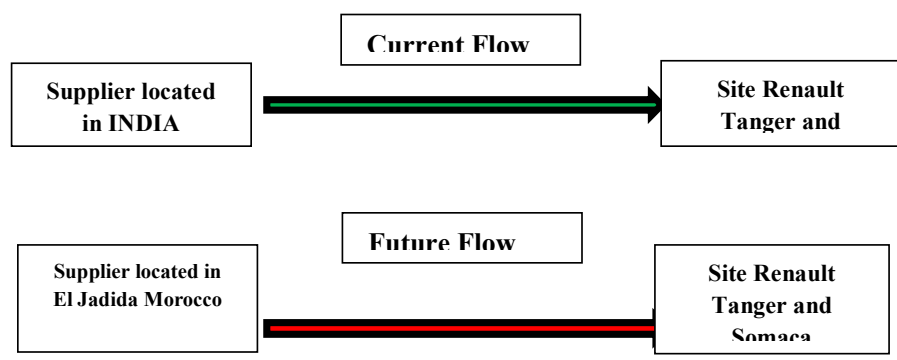

Figure 8: Logistic flows of radiator pipes

To compare the logistic costs of each stream there is a unit at Renault specializing in this transport encryption. It calculates the transport costs of the two flows.

The nature of the information collected for each reference is:

- The types of projects, in other words the different vehicles impacted.

- The weight of each reference: each reference has a specific weight. This information is provided by the engineering department of the company.

Daily rates: the volume that Renault wants to receive every day to avoid breaking the production chain.

- The code of the packaging unit (CPU): the type of CPU used in order to know the number of parts that this packaging unit can contain.

- The code of the handling unit (UM): the type of UM used in order to know the number of the CUs that the UM can contain.

- The supplier site account and the customer account.

After collecting this information from different departments, the launch of transport encryption for current flows will be possible.

After a kick off, the engineering department deducts the nature of the CUs and the UMs that the supplier must use since the transport is provided by Renault. Consequently, Renault launched the transport costing for this future flow.

The return of the two transport figures, made it possible to identify the transport gain that Renault can earn

The table below summarizes the results of the two streams. We cannot give all the details of transport gain for each reference because of confidentiality: 
What we can deduce is that the transport gain will be 5.51 euro for each family of parts delivered to the Renault plant.

For this purpose the Purchasing Department has established a current CA analysis and the prices that Renault pays for the radiator hoses in order to compare with the supplier's offer.

\section{Current turnover analysis:}

The reference prices appear on a platform called SCOPP, which manages supplier contracts, their appointment, and the prices of all sourced references as well as supplier flows.

The list of references will be sent to a cell specializing in the administration of this platform, in order to retrieve the prices of each reference.

The objective was to realize the impact of total turnover of references consulted and to know the amount that Renault currently pays. Here is the result of the analysis in the form of a table:

Table 9: Turnover analysis

\begin{tabular}{|c|c|}
\hline The parts/year & price \\
\hline $\begin{array}{c}\text { Radiator Inlet } \\
\text { Hose }\end{array}$ & $20000,00 €$ \\
\hline $\begin{array}{c}\text { Radiator Outlet } \\
\text { Hose }\end{array}$ & $10000,00 €$ \\
\hline Heat Inlet Hose \\
\hline $\begin{array}{c}\text { Hose outlet } \\
\text { radiator heating }\end{array}$ & $30000,00 €$ \\
\hline $\begin{array}{c}\text { Hose intake tank } \\
\text { degassing }\end{array}$ & $1000000,00 €$ \\
\hline $\begin{array}{c}\text { Hose outlet tank } \\
\text { degassing }\end{array}$ & $60000,00 €$ \\
\hline Hose purge & $20000,00 €$ \\
\hline TOTAL & $280000,00 €$ \\
\hline
\end{tabular}

The turnover shown in this table is the amount that Renault is paying today. Vis-à-vis its supplier, it is necessary to specify that this table summarizes the turnover for each type of radiator pipes.

Indeed, each type of radiator pipes corresponds to a sum of references. At the end we have specified in the project framework that there are 800 references for all radiator pipe parts.

\section{Supplier return}

The supplier return was set at the second week of April, unfortunately, Renault did not receive the supplier offer on time.

As a result, Renault relaunched its demand, and this time Renault received an unfavorable return which expresses that the quantity of references sent is very large and it will take a long time to encrypt them on the form of an industrial process. In addition it has even specified that to produce the quantity requested it will need very large investments which are very expensive and that the requested technology does not exist in Morocco. Therefore Renault must expatriate it from their site located in Ukraine. 
Rajaa Raissouni ,M'hamed Hamiche; The Rate of Local Integration in the Supply Chain of the Renault Maroc Company. Transactions on Machine Learning and Artificial Intelligence, Vol 5 No 4 August (2017); pp: 123-140

In short, Renault has deduced that the supplier is not competitive on all references.

\section{Conclusion}

Local sourcing is a very complicated process in non-industrialized countries. Thanks to a solid industrial fabric, an experience effect, and advanced technologies available within the country Renault was able to achieve a local integration rate of $90 \%$ in India.

The lack of technology and the effect of experience make it very difficult to establish local integration because investment costs are enormous. By default, the competitiveness of local suppliers in relation to international suppliers' prices will be impacted. Of course, ecosystem conventions have been established to solve this problem of non-competitiveness of local suppliers. This was possible through the subsidies that the Moroccan State undertakes to grant suppliers to encourage them to make the necessary investments.

Indeed, the problem of the departure was to know if the local sourcing always allows optimizing the purchase costs of the multinationals. To verify this hypothesis we have piloted a project of local integration for the multinational Renault.

We have found that local integration does not always optimize the purchasing costs of multinationals because of the lack of competitiveness of local suppliers, especially in developing countries.

\section{REFERENCES}

[1]. Op.cit., Bozarth, Handfield, Introduction to Operations and Supply Chain management, Pearson, 2007

[2]. Supply Chain Brain, U.S. and China Are the Riskiest Geographies for Sourcing and Manufacturing.

[3]. AberdeenGroup, Low-Cost Country Sourcing : Success Strategies Maximizing and Sustaining the Next Big Supply Savings Opportunity, Juin 2005

[4]. Sara Ireton, Global Sourcing Checklist. Industry Week, janvier 2007, p. 40

[5]. Mike Jones, Domestic costs of foreign sourcing. Material Handling Management, février 2008, p. 40-41

[6]. Sean Delaney, Delivering Value in both good and bad times, E-sourcing Forum, 14 juillet 2008

[7]. N. Sheth, « présentation d'un modèle de comportement des acheteurs industriels, Le Supplier Choice Model » WOODSID \& VYAS (1984;1986; 1987)

[8]. Roger Pérotin marketing achats, stratégies et tactiques, Edition 2010

[9]. SidhuSephardi, Sourcing strategy, principles, policy and designs, 2005, Springer

[10]. Salons Solutions, discussion informelle avec des décideurs, CNIT Paris La Défense, 30 septembre 2008.

[11]. Collectif, Encyclopédie de gestion, article "Stratégie d'entreprise et économie industrielle », écrit par A. Desreumaux, Economica, 1997. 